\title{
A randomized behavioural trial targeting glycaemic index improves dietary, weight and metabolic outcomes in patients with type 2 diabetes
}

\author{
Melissa Davis Gutschall ${ }^{1} \dagger$, Carla K Miller ${ }^{2, *} \ddagger$, Diane C Mitchell ${ }^{3}$ and \\ Frank R Lawrence ${ }^{4}$ \\ 'Department of Nutritional Sciences, Pennsylvania State University, University Park, PA 16802, USA: ${ }^{2}$ Penn State \\ Diabetes Center, Pennsylvania State University, University Park, PA 16802, USA: ${ }^{3}$ Diet Assessment Center, \\ Department of Nutritional Sciences, Pennsylvania State University, University Park, PA 16802, USA: ${ }^{4}$ Department \\ of Human Development and Family Studies, Pennsylvania State University, University Park, PA 16802, USA
}

Submitted 11 July 2008: Accepted 13 November 2008: First published online 23 January 2009

\begin{abstract}
Objective: Glycaemic index (GI) reflects the postprandial glucose response of carbohydrate-containing foods. A diet with lower GI may improve glycaemic control in people with diabetes. The purpose of the present study was to evaluate the change in outcomes following a behavioural intervention which promoted lower-GI foods among adults with diabetes.

Design: A pre-test-post-test control group design was used with participants randomly assigned to an immediate (experimental) or delayed (control) treatment group. The intervention included a 9-week, group-based intervention about carbohydrate and the glycaemic index. Dietary, anthropometric and metabolic measures were obtained pre/post-intervention in both groups and at 18-week follow-up for the immediate group.

Setting: The study was conducted in a rural community in the north-eastern USA. Subjects: Adults having type 2 diabetes mellitus for $\geq 1$ year, aged $40-70$ years and not requiring insulin therapy ( $n$ 109) were recruited.

Results: Following the intervention, mean dietary GI $(P<0 \cdot 001)$, percentage of energy from total fat $(P<0 \cdot 01)$ and total dietary fibre $(P<0 \cdot 01)$ improved in the immediate compared with the delayed group. Mean BMI $(P<0 \cdot 0001)$, fasting plasma glucose $(P=0.03)$, postprandial glucose $(P=0 \cdot 02)$, fructosamine $(P=0.02)$ and insulin sensitivity factor $(P=0.04)$ also improved in the immediate group compared with the delayed group. Mean waist circumference among males $(P<0 \cdot 01)$ and body weight among males and females $(P<0 \cdot 01)$ were significantly different between treatment groups.

Conclusions: Educating clients about carbohydrate and the glycaemic index can improve dietary intake and health outcomes among adults with type 2 diabetes.
\end{abstract}

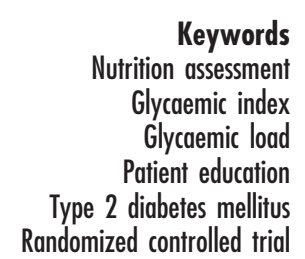

Diabetes affects approximately $9 \cdot 3 \%$ of the US population $^{(1)}$, and the number of people diagnosed with diabetes is projected to increase by $198 \%$ in $2050^{(2)}$. In people aged 35-64 years in the USA, excess mortality attributable to diabetes was $6-27 \%$ in $2000^{(3)}$. The need for effective strategies for managing diabetes and the subsequent sequelae are imperative.

$\uparrow$ Present address: Department of Foods \& Nutrition, Radford University, Radford, VA 24142, USA.

\$ Present and correspondence address: Department of Human Nutrition, Ohio State University, 325 Campbell Hall, 1787 Neil Avenue, Columbus, $\mathrm{OH} 43210$, USA.
Glycaemic index (GI) classifies carbohydrate-containing foods according to their glucose-raising potential, while glycaemic load (GL) reflects the total glycaemic effect of the diet ${ }^{(4,5)}$. GL can be lowered by reducing the amount of carbohydrate consumed, by choosing foods with lower GI, or by a combination of approaches. A diet with lower GI or GL may improve outcomes among people with diabetes ${ }^{(6)}$.

GI may play a role in preventing or treating type 2 diabetes by decreasing the risk for obesity or by altering metabolic endpoints ${ }^{(7,8)}$. Improvements in glycaemic control were observed in people with diabetes in a recent meta-analysis ${ }^{(9)}$. A lower-GI diet was shown to decrease 
postprandial glucose and insulin responses ${ }^{(10)}$ and improve serum lipid concentrations ${ }^{(11,12)}$. Lower-GL diets were associated with decreased risk for type 2 diabetes ${ }^{(13,14)}$, decreased levels of C-reactive protein and inflammation $^{(15,16)}$, and weight loss ${ }^{(8,17)}$

Prior research has evaluated the effect of interventions regarding GI among overweight adolescents ${ }^{(18)}$, people with type 1 diabetes ${ }^{(19)}$ and people with CVD $^{(20)}$. However, few randomized controlled trials have evaluated a behavioural intervention which addressed GI and GL in the clinical management of adults with type 2 diabetes, a population who would likely benefit from a lower-GL diet ${ }^{(21,22)}$. The change in dietary intake, markers of obesity and metabolic endpoints following an intervention which targets both the quantity and quality of carbohydrate requires further investigation. Therefore, the purpose of the present study was to implement a behavioural intervention which targeted the adoption of a lower-GL diet and evaluate the impact of the intervention. The intervention included training and skill-building in portion control and making lower-GI food choices in today's environment to achieve a lower-GL diet and did not provide food to participants.

\section{Experimental methods}

\section{Research design}

The study used a pre-test-post-test control group design in which participants were randomly assigned to an immediate or delayed group using a computer-generated random numbers table. The sequence of random allocation was concealed until the treatment group was assigned by programme staff. Due to the nature of the study, neither participants nor staff were blinded to group assignment.

Following the baseline assessment, the immediate group proceeded through a 9-week intervention. Participants in the delayed group served as a wait list control condition. All participants completed a second round of data collection at the end of the nine weeks. This 9-week treatment-control period served as an efficacy trial of the intervention by comparing initial differences between the experimental (immediate group) and control (delayed group) conditions following implementation of the intervention for the immediate group. Following data collection, the delayed group proceeded through the same 9-week intervention and a third round of data collection occurred at 18 weeks, after they had completed the intervention. Comparison of outcomes immediately before and after all participants completed the intervention enabled us to evaluate replication of the effects of the intervention between the immediate and delayed groups. The third assessment for the immediate group at the 18-week time point served as a measure of maintenance of change, as there was no contact between programme staff and participants during this period.
The study was designed to test the following hypotheses: (i) the immediate group would achieve greater improvement in outcomes than the delayed group during the initial 9-week treatment-control period; (ii) the delayed group would achieve similar improvements in outcomes as the immediate group at 18 weeks following the intervention; and (iii) the immediate group would sustain improvement in outcomes at 18 weeks during the maintenance period.

\section{Subjects}

Participants were eligible for the study if they were 40-70 years old, diagnosed with type 2 diabetes mellitus for at least one year, and did not require insulin therapy for diabetes management. Participants were recruited through local medical practices, newspaper and television advertisements, and the university newswire. All procedures were followed in accordance with the ethical standards of the sponsoring institution and participants provided written, informed consent.

\section{Measures}

Anthropometric, metabolic, physical activity and dietary measures were obtained. Height was measured using a wall-mounted stadiometer. The mean of two body weight measurements using a digital scale (Cardinal Scale Manufacturing Co., Webb City, MO, USA) with participants wearing light clothing and no shoes was determined. BMI, which measures weight adjusted for height, was calculated $\left(\mathrm{kg} / \mathrm{m}^{2}\right)$. Two waist circumference measurements were obtained at each visit and the mean was determined. These measurements were made at the end of a normal expiration by placing a non-elastic tape in a horizontal plane at the narrowest part of the torso, midway between the lower border of the rib cage and the iliac crest.

An overnight $12 \mathrm{~h}$ fasting blood sample was drawn by venepuncture. Plasma was centrifuged within $1 \mathrm{~h}$ and kept at $4^{\circ} \mathrm{C}$ until processing. Glucose and TAG were measured by standard enzymatic procedures and fructosamine was measured by colorimetric assay (Quest Diagnostics, Corporate HQ, Lyndhurst, NJ, USA). Serum insulin concentration was determined by RIA utilizing ${ }^{125}$ I-labelled human insulin and human insulin antiserum (General Clinical Research Center, Hershey Medical Center, Hershey, PA, USA). Insulin sensitivity factor (ISF) was calculated according to the quantitative insulin sensitivity check index ${ }^{(23)}$. Participants were asked to record their blood glucose at home using a glucometer before and 1.5 to $2 \mathrm{~h}$ after each meal three days prior to assessment visits to estimate postprandial glucose excursions. An approximation of postprandial glucose excursions was calculated as the mean difference between pre- and postprandial glucose values across the three days.

A general-purpose measure of physical activity, the Seven-Day Physical Activity Recall, was conducted to assess energy expenditure. Participants were queried 
about the frequency, intensity, time and type of physical activity for the previous seven days; an estimate of total energy expenditure per day was calculated. This measure was previously found to provide reliable estimates of energy expenditure ${ }^{(24,25)}$.

Three sets of $24 \mathrm{~h}$ dietary recalls were conducted using the Minnesota Nutrition Data System for Research (NDS-R version 2006; Nutrition Coordinating Center, University of Minnesota, Minneapolis, MN, USA) at each assessment period. A multiple-pass method was used to determine dietary intake and recalls took place on two weekdays and one weekend day selected at random over a two-week period. Each participant was provided with a two-dimensional food portion visual (2D Food Portion Visual; Nutrition Consulting Enterprises, Framingham, MA, USA) and instructed to use the visual and common household measures (e.g. measuring cups) to estimate portion sizes. The interviewers were blinded to treatment condition and had no face-to-face contact with study participants. Nutrient intakes of participants' diets were calculated based on the three-day mean from each assessment period. GI values were obtained from published sources ${ }^{(26)}$. Methods for assigning GI values to foods with unpublished values followed the procedures described elsewhere ${ }^{(27,28)}$. LowGI foods are defined as having a value $<56$, medium-GI foods have a value of 56-69, and high-GI foods have a value $\geq 70^{(29)}$.

\section{Nutrition intervention}

The intervention included nine weekly group sessions lasting 1.5 to $2 \mathrm{~h}$ each. A lower-GL diet can be achieved by limiting carbohydrate intake and/or by incorporating lower-GI foods into the diet. The intervention focused on selecting lower-GI foods instead of restricting carbohydrate intake to avoid severely restricting food groups with a low-carbohydrate diet. The 9-week curriculum progressed through the topics of self-monitoring food intake and blood glucose, monitoring portion sizes of food to control carbohydrate intake, goal-setting principles for establishing achievable goals, carbohydrate counting to control carbohydrate distribution and intake, making lower-GI food substitutions, factors which affect the GI value of food, and maintaining behavioural change. Participants set a self-selected goal at the end of most group sessions. The completion of written self-monitoring records was encouraged at least four days per week to help participants determine the impact of dietary change on glycaemic control. These monitoring records were reviewed weekly by programme staff and participants received individualized feedback.

\section{Statistical analyses}

The distributions of outcome variables were inspected for normality and met the assumptions required for subsequent analyses. Three participants were removed from the TAG analysis due to a value $>8 \mathrm{mmol} / \mathrm{l}$ and two participants were removed from the insulin and ISF analyses due to an insulin value $>650 \mathrm{pmol} / 1$. ANOVA was used to compare the mean change between the immediate and delayed groups for the initial 9-week treatment-control period and for the pre-post intervention period. Comparison of change in outcomes was conducted between groups immediately before and after the intervention to determine replication of the effects of the intervention for the delayed group compared with the initial changes made by the immediate group. A paired $t$ test was used to examine change in outcomes from the 9-week post-intervention assessment to the 18-week follow-up assessment for the immediate group only. All analyses were conducted using the SAS statistical software package version $9 \cdot 1$ (SAS Institute, Inc., Cary, NC, USA), and the level of significance was set at $P<0 \cdot 05$.

A primary purpose of the intervention was to promote the adoption of a lower-GL diet by encouraging the adoption of low-GI food choices. To detect a medium effect size between groups for dietary GI based on Cohen's criterion of 0.5 with $80 \%$ probability $^{(30)}$, the estimated sample size was 128 participants.

\section{Results}

One hundred and eighty-two people were assessed for eligibility via a telephone screening protocol. Forty-five of those did not meet inclusion criteria and twenty-eight were not interested in participating. One hundred and nine people were randomized, 103 participated in the intervention and ninety-nine completed data collection. There were no significant differences in demographic characteristics between those who did and did not complete the study.

There were no significant differences in sample characteristics (Table 1), prescribed medications or the amount of physical activity reported between the immediate and delayed groups throughout the study. Participants attended a mean of $7 \cdot 7$ (SD 1.6) out of nine intervention sessions and kept self-monitoring records for a mean of 3.7 (SD 1.3) $\mathrm{d}$ /week with no difference in attendance or monitoring records between the immediate and delayed groups.

No differences in dietary intake were observed between groups at baseline (Table 1). During the initial 9-week treatment-control period, the mean change in GL for the immediate group was not significantly different from the delayed group $(P=0 \cdot 39$; Table 2$)$. The change in GI $(P<0 \cdot 001)$, total dietary fibre $(P=0 \cdot 002)$ and the percentages of energy from protein $(P=0 \cdot 02)$, total fat $(P=0.003)$, saturated fat $(P=0.03)$ and monounsaturated fat $(P=0.006)$ between groups was significantly different. The change in GI between groups represents a large effect size ${ }^{(30)}$. At 18 weeks following replication of the intervention for the delayed group, 
Table 1 Characteristics of the study sample at baseline: $40-70$-year-old adults having type 2 diabetes mellitus for $\geq 1$ year and not requiring insulin therapy ( $n$ 103), rural north-east USA

\begin{tabular}{|c|c|c|c|c|c|}
\hline \multirow[b]{2}{*}{ Variable } & \multicolumn{2}{|c|}{ Immediate group ( $n 55)$} & \multicolumn{2}{|c|}{ Delayed group ( $n$ 48) } & \multirow[b]{2}{*}{$P$ value } \\
\hline & \multicolumn{2}{|c|}{$\%$} & \multicolumn{2}{|c|}{$\%$} & \\
\hline \multicolumn{6}{|l|}{ Sample characteristics } \\
\hline Female & & & & & 0.42 \\
\hline Caucasian & & & & & $0 \cdot 87$ \\
\hline Married & & & & & 0.99 \\
\hline College degree & & & & & $0 \cdot 41$ \\
\hline \multirow[t]{2}{*}{ Employed full-time } & \multicolumn{2}{|c|}{$60 \cdot 0$} & \multicolumn{2}{|c|}{$63 \cdot 8$} & 0.56 \\
\hline & Mean & SD & Mean & SD & \\
\hline Age (years) & $58 \cdot 6$ & $7 \cdot 7$ & $59 \cdot 8$ & $7 \cdot 3$ & $0 \cdot 41$ \\
\hline Years diagnosed with diabetes & $4 \cdot 7$ & $4 \cdot 8$ & $4 \cdot 7$ & 3.9 & 0.99 \\
\hline \multicolumn{6}{|l|}{ Energy and nutrient intake } \\
\hline Glycaemic load* & 109 & $39 \cdot 9$ & 113 & $37 \cdot 3$ & 0.52 \\
\hline Glycaemic indext & 56 & $6 \cdot 1$ & 55 & $5 \cdot 7$ & $0 \cdot 19$ \\
\hline Energy (kJ) & $7447 \cdot 9$ & $2250 \cdot 6$ & $7686 \cdot 0$ & $2223 \cdot 8$ & 0.59 \\
\hline Energy (kcal) & $1780 \cdot 1$ & $537 \cdot 9$ & $1837 \cdot 0$ & $531 \cdot 5$ & 0.59 \\
\hline Carbohydrate (\% of energy) & $44 \cdot 6$ & $9 \cdot 0$ & $45 \cdot 6$ & $10 \cdot 4$ & 0.59 \\
\hline Protein (\% of energy) & $18 \cdot 6$ & $3 \cdot 2$ & $18 \cdot 3$ & $3 \cdot 8$ & $0 \cdot 67$ \\
\hline Total fat (\% of energy) & $38 \cdot 4$ & $7 \cdot 3$ & $36 \cdot 2$ & $8 \cdot 3$ & $0 \cdot 17$ \\
\hline Saturated fat ( $\%$ of energy) & $12 \cdot 3$ & $3 \cdot 2$ & $12 \cdot \overline{3}$ & $3 \cdot 0$ & 0.98 \\
\hline Polyunsaturated fat (\% of energy) & $8 \cdot 6$ & $2 \cdot 5$ & $7 \cdot 6$ & $3 \cdot 2$ & 0.09 \\
\hline Monounsaturated fat ( $\%$ of energy) & $14 \cdot 5$ & $3 \cdot 2$ & $13 \cdot 5$ & $3 \cdot 4$ & $0 \cdot 14$ \\
\hline Cholesterol $(\mathrm{mg} / 4184 \mathrm{~kJ})$ & $187 \cdot 5$ & $91 \cdot 0$ & $166 \cdot 3$ & $84 \cdot 1$ & $0 \cdot 23$ \\
\hline Total fibre $(\mathrm{g} / 4184 \mathrm{~kJ})$ & $11 \cdot 0$ & $3 \cdot 2$ & $10 \cdot 4$ & $3 \cdot 2$ & $0 \cdot 34$ \\
\hline Insoluble fibre (g/4184 kJ) & $8 \cdot 0$ & $2 \cdot 6$ & $7 \cdot 5$ & $2 \cdot 7$ & $0 \cdot 39$ \\
\hline Soluble fibre $(\mathrm{g} / 4184 \mathrm{~kJ})$ & $2 \cdot 9$ & $0 \cdot 8$ & $2 \cdot 7$ & $0 \cdot 8$ & $0 \cdot 35$ \\
\hline Total sugars (g/4184 kJ) & $42 \cdot 5$ & $3 \cdot 2$ & $45 \cdot 3$ & $13 \cdot 6$ & $0 \cdot 32$ \\
\hline Added sugars (g/4184 kJ) & $22 \cdot 5$ & $13 \cdot 8$ & $24 \cdot 2$ & $10 \cdot 6$ & 0.50 \\
\hline \multicolumn{6}{|l|}{ Anthropometric measures } \\
\hline \multicolumn{6}{|l|}{ Weight $(\mathrm{kg})$} \\
\hline Females & $84 \cdot 5$ & $17 \cdot 3$ & $92 \cdot 8$ & $19 \cdot 2$ & 0.09 \\
\hline Males & $108 \cdot 7$ & $23 \cdot 9$ & $101 \cdot 3$ & $16 \cdot 4$ & $0 \cdot 23$ \\
\hline \multicolumn{6}{|l|}{ Waist circumference $(\mathrm{cm})$} \\
\hline Females & $110 \cdot 1$ & $14 \cdot 3$ & $116 \cdot 6$ & $15 \cdot 3$ & $0 \cdot 10$ \\
\hline Males & $116 \cdot 6$ & $15 \cdot 9$ & $112 \cdot 7$ & $13 \cdot 1$ & $0 \cdot 38$ \\
\hline BMI $\left(\mathrm{kg} / \mathrm{m}^{2}\right)$ & $33 \cdot 4$ & $6 \cdot 9$ & $34 \cdot 0$ & $6 \cdot 0$ & 0.63 \\
\hline \multicolumn{6}{|l|}{ Metabolic measures } \\
\hline TAG $(\mathrm{mmol} / \mathrm{l})$ & $1 \cdot 9$ & 0.9 & 1.9 & $0 \cdot 8$ & $0 \cdot 70$ \\
\hline Fructosamine $(\mu \mathrm{mol} / \mathrm{l})$ & $258 \cdot 5$ & $54 \cdot 0$ & $267 \cdot 4$ & $48 \cdot 7$ & $0 \cdot 38$ \\
\hline Fasting plasma glucose $(\mathrm{mmol} / \mathrm{l})$ & $8 \cdot 3$ & $2 \cdot 5$ & $8 \cdot 7$ & $2 \cdot 1$ & $0 \cdot 39$ \\
\hline Insulin (pmol/l) & $134 \cdot 0$ & $68 \cdot 5$ & $130 \cdot 6$ & $87 \cdot 8$ & $0 \cdot 83$ \\
\hline Insulin sensitivity factor§ & $0 \cdot 3$ & $0 \cdot 0$ & $0 \cdot 3$ & 0.0 & 0.51 \\
\hline Preprandial capillary glucose $(\mathrm{mmol} / \mathrm{l}) \|$ & $7 \cdot 0$ & 1.9 & $7 \cdot 4$ & $1 \cdot 2$ & $0 \cdot 34$ \\
\hline Postprandial capillary glucose $(\mathrm{mmol} / \mathrm{l}) \|$ & $9 \cdot 0$ & $2 \cdot 7$ & $9 \cdot 4$ & 1.5 & 0.47 \\
\hline Pre-postprandial blood glucose excursion $(\mathrm{mmol} / \mathrm{l}) \|$ & $2 \cdot 1$ & $1 \cdot 2$ & $1 \cdot 9$ & $1 \cdot 0$ & $0 \cdot 46$ \\
\hline
\end{tabular}

${ }^{*}$ Glycaemic load $(G L)=($ Gl value of the food $\times$ grams of carbohydrate from the food $) / 100$; summed for all foods to get daily glycaemic load, averaged over $3 \mathrm{~d}$ of intake.

tGlycaemic index $(\mathrm{Gl})=$ (grams of carbohydrate from food item/total daily grams of carbohydrate) $\times \mathrm{Gl}$ of the food item; summed for all foods to get daily Gl, averaged over $3 \mathrm{~d}$ of intake. Gl values are based on glucose as the reference with glucose $=100$.

$\$$ Insulin sensitivity was calculated according to the quantitative insulin sensitivity check index $\left(Q U I C K I=1 /\left[\log \left(I_{0}\right)+\log \left(G_{0}\right)\right]\right.$, where $I_{0}$ is the fasting insulin $(\mu U / m I)$ and $\mathrm{G}_{0}$ is the fasting glucose $\left.(\mathrm{mg} / \mathrm{dll})\right)$.

IISelf-reported monitoring records collected before and after meals for $3 \mathrm{~d}$. Twenty-nine participants in the immediate group and twenty-four in the delayed group provided complete records for this analysis ( $n$ 53).

changes in nutrient intake in the delayed group were not significantly different from those made by the immediate group except for the percentage of energy from saturated fat $(P=0.03)$. Total $(P=0.03)$ and insoluble fibre density $(P=0.02)$ declined significantly at 18 weeks during the maintenance period for the immediate group.

Both males and females in the immediate group lost weight, while participants in the delayed group gained weight during the initial 9-week treatment-control period (Table 3). Similarly, males in the immediate group experienced a mean $(\mathrm{SE})$ decrease in waist circumference $(-3.6(1 \cdot 1) \mathrm{cm})$ while males in the delayed group experienced an increase $(0.8(0.8) \mathrm{cm} ; P=0.002)$. Significant differences between the immediate and delayed groups for BMI $\left(-0 \cdot 8(0 \cdot 2) v \cdot 0 \cdot 1(0 \cdot 1) \mathrm{kg} / \mathrm{m}^{2} ; P<0 \cdot 0001\right)$, fructosamine $(-5 \cdot 0(4 \cdot 6) v \cdot 10 \cdot 6(4 \cdot 4) \mu \mathrm{mol} / \mathrm{l} ; P=0 \cdot 02)$, fasting plasma glucose $(-0 \cdot 5(0 \cdot 2) \quad v \cdot 0 \cdot 1(0 \cdot 2) \mathrm{mmol} / \mathrm{l}$; $P=0 \cdot 03)$, postprandial glucose $(-1 \cdot 2(0 \cdot 2) v \cdot-0 \cdot 2(0 \cdot 4)$ $\mathrm{mmol} / \mathrm{l} ; P=0.02)$ and ISF $(0.0002(0.0002) v .-0 \cdot 0004$ $(0 \cdot 0002) ; P=0 \cdot 04)$ were observed at 9 weeks. Mean BMI, 


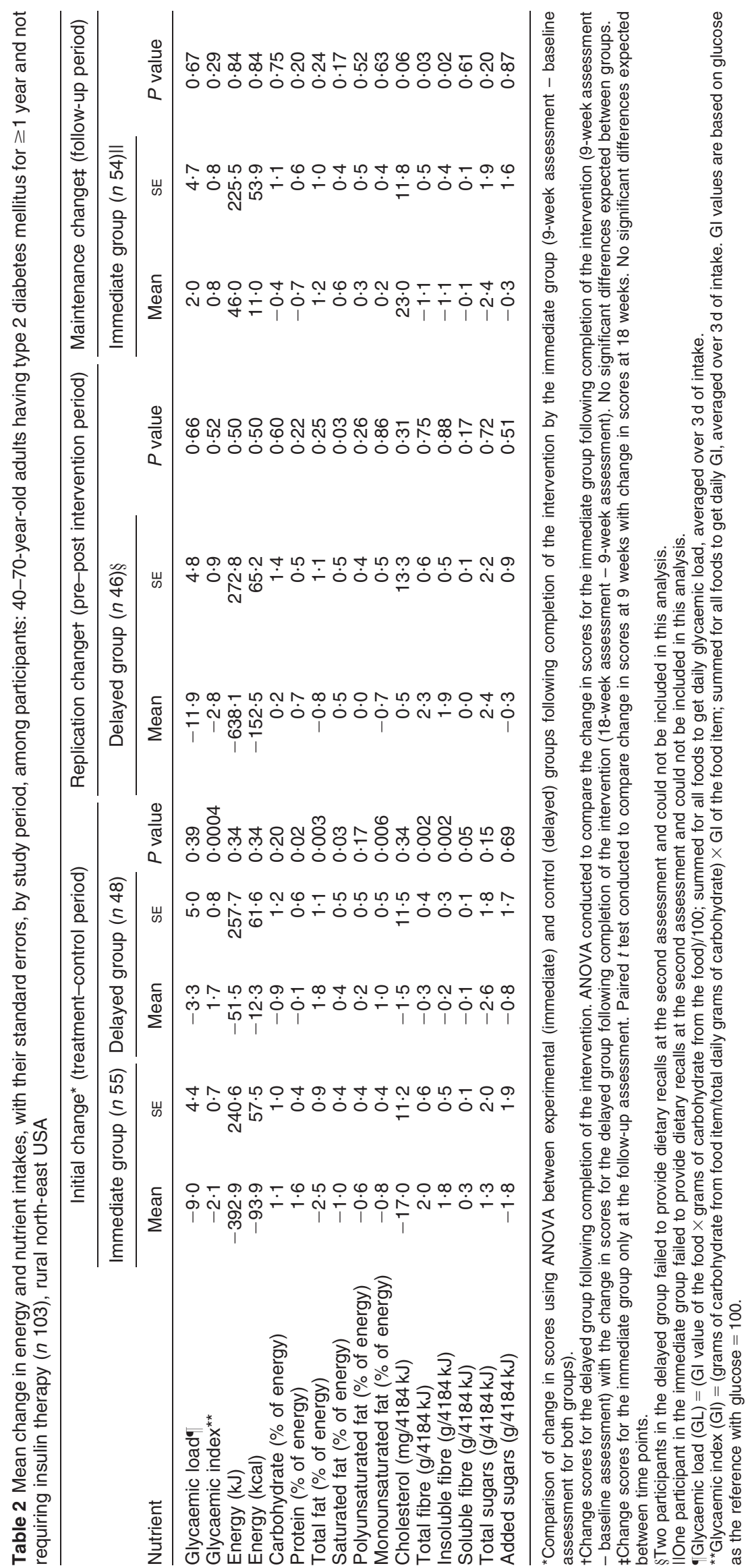




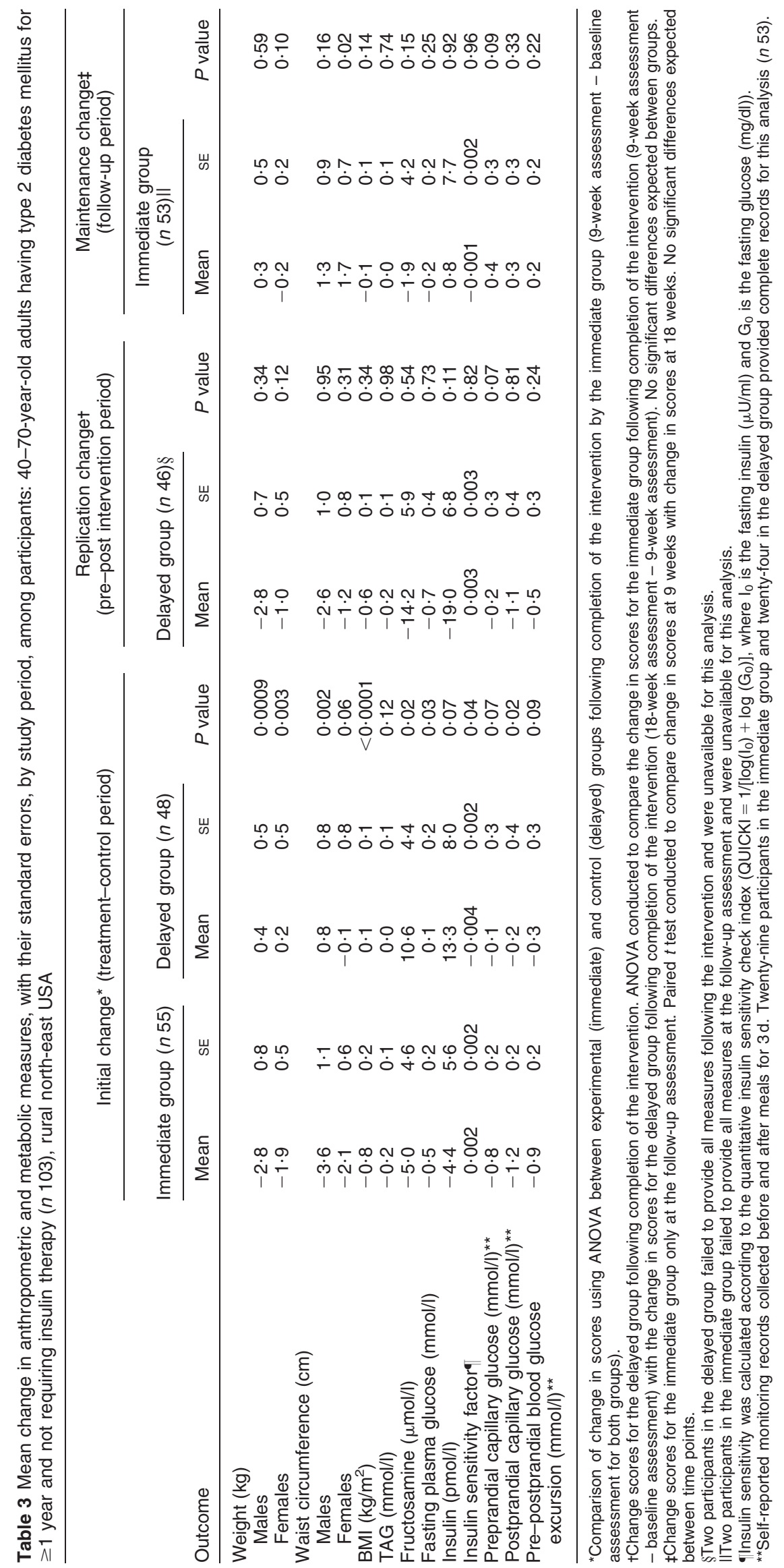


fructosamine, fasting plasma glucose and insulin increased in the delayed group during the control period. Likewise, insulin sensitivity decreased for the delayed group during the control period but increased for the immediate group. At 18 weeks, similar mean decreases in body weight, waist circumference, glucose, fructosamine and TAG were observed for the delayed group as for the immediate group following the intervention. At 18 weeks, a significant mean (SE) increase in waist circumference for females in the immediate group $(1.7(0.7) \mathrm{cm} ; P=0.02)$ was observed (Table 3).

\section{Discussion}

Few studies have evaluated a behavioural intervention regarding GL in diabetes management. While there was not a significant difference in GL between groups following the intervention, participants' intake of dietary fibre and fat improved with a concomitant reduction in GI. The modest decline in GL was achieved without a significant decline in the percentage of energy from carbohydrate. Total fibre, particularly insoluble fibre, density increased. This may in part be due to decreased energy intake but also due to incorporating more high-fibre foods into the diet. There were small but significant increases in whole fruit and whole grain servings and a decrease in refined grain servings following the intervention (data not shown). In addition, a greater decline in GL may not have been feasible given the relatively low percentage of energy from carbohydrate in participants' diets at baseline.

The GI and GL values in the present study were lower than many of the values reported previously for other population groups ${ }^{(28)}$. Estimates of dietary GI at baseline in the present study were similar to the GI achieved at study end previously ${ }^{(21,22)}$. However, participants made further reductions in GI following the intervention, which incorporated meal planning activities to promote the substitution of lower- for higher-GI foods. Specific changes in servings of food groups consumed during the study are reported elsewhere ${ }^{(31)}$.

Moreover, GI improved following the intervention even though the topic of GI was not discussed until week six of the 9-week intervention. Perhaps incorporating instruction about lower-GI substitutions into earlier lessons and/or giving a specific recommendation for the number of low-GI foods to consume daily would facilitate even greater improvements in dietary GI. Participants in the present study were encouraged to substitute lowerfor higher-GI foods but were not given a specific goal regarding the number of low-GI foods to consume. The modest decline in GI in the study may be realistic given the brief time frame available for participants to apply the concept of GI to food choices. Participants may need more than a few weeks to apply a new behaviour, receive feedback and realign their efforts even when specific goals are provided.

The change in dietary fat intake, particularly in the immediate group, was unexpected as dietary fat was not addressed during the intervention. Lower fat intake may be related to food choices characteristic of a lower-GI or -GL diet in general. Previous reports described a lower percentage of energy from fat among participants counselled to choose lower-GI foods ${ }^{(19,21,32)}$. Participants may have become aware of their fat intake and the overall quality of their diet through the self-monitoring emphasized. Prior research found that self-monitoring positively influenced weight control $^{(33,34)}$. While participants did not record fat intake in the present study, the recording of foods consumed likely helped participants focus on the quality of their food choices.

The differences in dietary outcomes were accompanied by changes in anthropometric outcomes. A reduction in weight and BMI in both men and women and a reduction in waist circumference in men occurred even though a low-energy diet was not prescribed and participants were not given a predetermined diet to follow. The weight reduction observed in the present study was similar to the change in weight $(-1.0$ to $-1.9 \mathrm{~kg})$ in other short-term intervention studies ${ }^{(20,21,35,36)}$. The emphasis on portion control in the current study likely facilitated the weight loss observed. Additional research is needed to determine whether a lower-GI or -GL diet can help people with diabetes achieve and sustain weight loss.

Improvements in glycaemic control also were observed following the intervention. The sample was in good glycaemic control at baseline based on the mean fasting glucose values. Glycosylated $\mathrm{Hb}$ (HbA1c) was not assessed for the study given the brief time period of the intervention. However, the mean fasting glucose value for the sample at baseline is equivalent to an HbA1c of $7 \cdot 0 \%$. The American Diabetes Association recommends an HbA1c of $<7 \cdot 0 \%$ for people with diabetes to minimize the risk for microvascular and neuropathic complications ${ }^{(37)}$. A meta-analysis of lower-GI diets in diabetes management found a reduction in $\mathrm{HbA} 1 \mathrm{c}$ of $0.43 \%$ when compared with higher-GI diets ${ }^{(9)}$. The change in fasting glucose in the present study corresponds to a decrease in $\mathrm{HbA} 1 \mathrm{c}$ of $0 \cdot 3 \%^{(38)}$. Future research is needed to determine the impact of the intervention in more poorly controlled diabetic patients. The changes obtained in the present study could translate into notable public health benefits at the population level.

Participants in the delayed group gained weight and experienced deterioration in fructosamine, fasting glucose and insulin prior to starting the intervention. Not only were reductions in anthropometric measures, glucose, insulin and fructosamine observed following the intervention, but these reductions compensated for the deterioration in outcomes during the initial 9-week control period. Our results suggest that, without intervention, the trajectory of 
change in weight and glycaemic control is worrisome and patients may continue to experience a decline in these outcomes. Educational methods for supporting patients with diabetes long-term beyond the immediate period following diagnosis are needed.

The decline in fibre intake and gain in waist circumference in females in the immediate group during the maintenance period following the intervention is concerning. Maintenance of behavioural change poses a challenge for most intervention studies ${ }^{(39,40)}$. A recent meta-analysis of diabetes self-management education found that $23.6 \mathrm{~h}$ of contact between the educator and patient are required to achieve significant improvement in glycaemic control ${ }^{(41)}$. Identification of the most salient factors, methods and frequency of contact which promote long-term maintenance of change is greatly needed, especially for a complex disease such as diabetes that requires extensive self-management.

Several limitations of the study should be noted. The impact of nutrition education regarding the adoption of lower-GI foods on dietary intake and health outcomes should be determined in a culturally diverse sample. The sample in the present study included primarily Caucasians in good glycaemic control. The effectiveness of the intervention in a sample of adults with diabetes in poor glycaemic control or those newly diagnosed with the disease should be evaluated. The intervention provided addressed portion control, self-monitoring, and controlling both the quantity and quality of carbohydrate consumed. The impact of an intervention which targeted only the adoption of lower-GI foods without addressing the quantity of carbohydrate to consume also should be determined. Finally, the impact of an intervention which targets the adoption of lower-GI foods compared with an intervention which targets a different dietary or nutrient goal (e.g. a reduced-fat diet) cannot be determined from the present study.

In summary, nutrition education regarding the adoption of a lower-GI and -GL diet can improve nutrient intake and modest nutrient changes may be associated with improved body weight and metabolic outcomes in adults with type 2 diabetes. A lower-GI diet is not overly complex for participants to adopt, and dietary quality does not necessarily diminish with the adoption of a lower-GI diet. Improvements in outcomes likely require continued behavioural intervention and support to be maintained, especially for a chronic disease such as diabetes. Further research is needed to determine the most effective method and frequency of contact for maintaining behavioural change following a short-term intervention.

\section{Acknowledgements}

This research was partially supported by the Hertzler Grant for Intervention Research from the American Dietetic
Association Foundation, the California Raisin Marketing Board, and NIH Grant M01 RR 10732. The services provided by the General Clinical Research Center of The Pennsylvania State University are appreciated. There are no conflicts of interest for the authors. The authors' responsibilities were as follows: M.D.G. and C.K.M. designed the study, conducted the intervention, interpreted the results and wrote the paper; D.C.M. coordinated the collection and analyses of the dietary data; F.R.L. assisted with data analyses and interpretation.

\section{References}

1. Narayan KMV, Boyle JP, Geiss LS, Saaddine JB \& Thompson TJ (2006) Impact of recent increase in incidence on future diabetes burden: US, 2005-2050. Diabetes Care 29, 2114-2116.

2. Cowie CC, Rust KF, Byrd-Holt DD, Eberhardt MS, Flegal KM, Engelgau MM, Saydah S, Williams DE, Geiss LS \& Gregg EW (2006) Prevalence of diabetes and impaired fasting glucose in adults in the US population: National Health and Nutrition Examination Survey 1999-2002. Diabetes Care 29, 1263-1268.

3. Roglic G, Unwin N, Bennett PH, Mathers C, Tuomilehto J, Nag S, Connolly V \& King H (2005) The burden of mortality attributable to diabetes: realistic estimates for the year 2000 . Diabetes Care 28, 2130-2135.

4. Liu S, Manson JE, Stampfer MJ, Holmes M, Hu FB, Hankinson SE \& Willett WC (2001) Dietary glycemic load assessed by food-frequency questionnaire in relation to plasma high-density-lipoprotein cholesterol and fasting plasma triacylglycerols in postmenopausal women. Am J Clin Nutr 73, 560-566.

5. Jenkins DJA, Kendall CWC, Augustin LSA, Franceschi S, Hamidi M, Marchie A, Jenkins AL \& Mette A (2002) Glycemic index: overview of implications in health and disease. Am J Clin Nutr 76, Suppl., 266S-273S.

6. Sheard NF, Clark NG, Brand-Miller JC, Franz MJ, Pi-Sunyer FX, Mayer-Davis E, Kulkarni K \& Geil P (2004) Dietary carbohydrate (amount and type) in the prevention and treatment of diabetes. Diabetes Care 27, 2266-2271.

7. Ludwig DS (2003) Dietary glycemic index and the regulation of body weight. Lipids 38, 117-121.

8. Thomas DE, Elliot E \& Baur L (2007) Low glycaemic index or low glycaemic load diets for overweight and obesity. Cochrane Database Syst Rev issue 3, CD005105.

9. Brand-Miller J, Hayne S, Petocz P \& Colagiuri S (2003) Lowglycemic index diets in the management of diabetes: a meta-analysis of randomized controlled trials. Diabetes Care 26, 2261-2267.

10. Jarvi AE, Karlstrom BE, Granfeldt YE, Bjorck IE, Asp NL \& Vessby BOH (1999) Improved glycemic control and lipid profile and normalized fibrinolytic activity on a lowglycemic index diet in type 2 diabetic patients. Diabetes Care 22, 10-18.

11. Liese AD, Gilliard T, Schulz M, D'Agostino RB Jr \& Wolever TM (2007) Carbohydrate nutrition, glycaemic load, and plasma lipids: the Insulin Resistance Atherosclerosis Study. Eur Heart J 28, 80-87.

12. Ma Y, Li Y, Chiriboga DE, Olendzki BC, Hebert JR, Li W, Leung K, Hafner AR \& Ockene IS (2006) Association between carbohydrate intake and serum lipids. J Am Coll Nutr 25, 155-163.

13. Salmeron J, Ascherio A, Rimm EB, Colditz GA, Spiegelman D, Jenkins DJ, Stampfer MJ, Wing AL \& Willett WC (1997) Dietary fiber, glycemic load and risk of NIDDM in men. Diabetes Care 20, 545-550. 
14. Salmeron J, Manson JE, Stampfer MJ, Colditz GA, Wing AL \& Willett WC (1997) Dietary fiber, glycemic load, and risk of non-insulin-dependent diabetes mellitus in women. JAMA 277, 472-477.

15. Liu S, Manson JE, Buring JE, Stampfer MJ, Willett WC \& Ridker PM (2002) Relation between a diet with a high glycemic load and plasma concentrations of high-sensitivity C-reactive protein in middle-aged women. Am J Clin Nutr 75, 492-498.

16. Qi L \& Hu FB (2007) Dietary glycemic load, whole grains, and systemic inflammation in diabetes: the epidemiological evidence. Curr Opin Lipidol 18, 3-8.

17. Ebbeling CB, Leidig MM, Sinclair KB, Hangen JP \& Ludwig DS (2003) A reduced-glycemic load diet in the treatment of adolescent obesity. Arch Pediatr Adolesc Med 157, 773-779.

18. Ebbeling CB, Leidig MM, Feldman HA, Lovesky MM \& Ludwig DS (2007) Effects of a low-glycemic load vs low-fat diet in obese young adults: a randomized trial. JAMA 297, 2092-2102.

19. Gilbertson HR, Brand-Miller JC, Thorburn AW, Evans S, Chondros P \& Werther GA (2001) The effect of flexible low glycemic index dietary advice versus measured carbohydrate exchange diets on glycemic control in children with type 1 diabetes. Diabetes Care 24, 1137-1143.

20. Frost GS, Brynes AE, Bovill-Taylor C \& Dornhorst A (2004) A prospective randomized trial to determine the efficacy of a low glycaemic index diet given in addition to healthy eating and weight loss advice in patients with coronary heart disease. Eur J Clin Nutr 58, 121-127.

21. Frost G, Wilding J \& Beecham J (1994) Dietary advice based on the glycaemic index improves dietary profile and metabolic control in type 2 diabetic patients. Diabet Med 11, 397-401.

22. Brand JC, Colagiuri S, Crossman S, Allen A, Roberts DCK \& Truswell AS (1991) Low-glycemic index foods improve long-term glycemic control in NIDDM. Diabetes Care 14, 95-101.

23. Katz A, Nambi SS, Mather K, Baron AD, Follmann DA, Sullivan G \& Quon MJ (2000) Quantitative insulin sensitivity check index: a simple, accurate method for assessing insulin sensitivity in humans. J Clin Endocrinol Metab 85, 2402-2410.

24. Sallis JF, Haskell WL, Wood PD, Fortmann SP, Rogers T, Blair SN \& Paffenbarger RS (1985) Physical activity assessment methodology in the Five-City Project. Am J Epidemiol 121, 91-106.

25. Blair SN, Haskell WL, Ho P, Paffenbarger RS, Vranizan KM, Farquhar JW \& Wood PD (1985) Assessment of habitual physical activity by a seven-day recall in a community survey and controlled experiments. Am J Epidemiol 122, 794-804.

26. Foster-Powell K, Holt SH \& Brand-Miller JC (2002) International table of glycemic index and glycemic load values: 2002. Am J Clin Nutr 76, 5-56.

27. Flood A, Subar AF, Hull SG, Zimmerman TP, Jenkins DJA \& Schatzkin A (2006) Methodology for adding glycemic load values to the National Cancer Institute Diet History Questionnaire database. J Am Diet Assoc 106, 393-402.
28. Olendzki BC, Ma Y, Culver AL, Ockene IS, Griffith JA, Hafner AR \& Hebert JR (2006) Methodology for adding glycemic index and glycemic load values to 24 -hour recall database. Nutrition 22, 1087-1095.

29. Brand-Miller JC, Wolever TMS, Foster-Powell K \& Colagiuri S (2003) The New Glucose Revolution. New York: Marlowe and Company.

30. Cohen J (1988) Statistical Power Analysis for the Behavioral Sciences, 2nd ed. Hillsdale, NJ: Lawrence Earlbaum Associates.

31. Miller CK, Gutschall MD \& Mitchell DC (2009) Change in food choices following a glycemic load intervention in adults with type 2 diabetes. J Am Diet Assoc (In the Press).

32. Amano Y, Sugiyama M, Lee JS, Kawakubo K, Mori K, Tang AC \& Akabayashi A (2007) Glycemic index-based nutritional education improves blood glucose control in Japanese adults: a randomized controlled trial. Diabetes Care 30, 1874-1876.

33. Mullen PD, Simons-Morton DG, Ramirez G, Frankowski RF, Green LW \& Mains DA (1997) A meta-analysis of trials evaluating patient education and counseling for three groups of preventive health behaviors. Patient Educ Couns 32, 157-173.

34. Yon BA, Johnson RK, Harvey-Berino J, Gold BC \& Howard AB (2007) Personal digital assistants are comparable to traditional diaries for dietary self-monitoring during a weight loss program. J Behav Med 30, 165-175.

35. Jimenez-Cruz A, Bacardi-Gascon M, Turnbull WH, RosalesGaray P \& Severino-Lugo I (2003) A flexible, low-glycemic index Mexican-style diet in overweight and obese subjects with type 2 diabetes improves metabolic parameters during a 6-week treatment period. Diabetes Care 26, 1967-1970.

36. Sloth B, Krog-Mikkelsen I, Flint A, Tetens I, Bjorck I, Vinoy S, Elmstahl H, Astrup A, Lang V \& Raben A (2004) No difference in body weight decrease between a lowglycemic-index and a high-glycemic-index diet but reduced LDL cholesterol after 10-wk ad libitum intake of the low-glycemic-index diet. Am J Clin Nutr 80, 337-347.

37. American Diabetes Association (2008) Executive summary: standards of medical care in diabetes - 2008. Diabetes Care 31, Suppl. 1, S5-S11.

38. Rohlfing CL, Wiedmeyer HM, Little RR, England JD, Tennill A \& Goldstein DE (2002) Defining the relationship between plasma glucose and HbA1c. Diabetes Care 25, 275-278.

39. Norris SL, Zhang X, Avenell A, Gregg E, Bowman B, Serdula M, Brown TJ, Schmid CH \& Lau J (2004) Long-term effectiveness of lifestyle and behavioral weight loss interventions in adults with type 2 diabetes: a metaanalysis. Am J Med 117, 762-774.

40. Svetkey LP, Stevens VJ, Brantley PJ et al. (2008) Comparison of strategies for sustaining weight loss: the weight loss maintenance randomized controlled trial. JAMA 299, $1139-1148$.

41. Norris SL, Lau J, Smith SJ, Schmid CH \& Engelgau MM (2002) Self-management education for adults with type 2 diabetes: a meta-analysis of the effect on glycemic control. Diabetes Care 25, 1159-1171. 